\title{
Durability of the adhesive cementation to the dentin substract
}

\author{
Durabilidade da cimentação adesiva ao substrato dentinário
}

\section{Rodivan BRAZ ${ }^{1}$}

Márcia de Almeida DURÃO'

Gabriela Luna Santana GOMES ${ }^{1}$

Fabio Barbosa DE SOUZA²

Eliane Alves LIMA ${ }^{1}$

\section{ABSTRACT}

\section{Objective}

The aim of this study was to evaluate, in vitro, the union stability of resin cements to the dental substract through microtensile bond strength ( $\mu T B S)$ analysis and scanning electron microscopy (SEM).

\section{Methods}

Fifty-four third human molars, stored in water for a short (24 hours) and long period of time (1 year) presented a flat oclusal superficial dentin. The teeth were distributed in six different groups: G1- Panavia F2.0/Kuraray; G2- RelyXUnicem/3M ESPE; G3- G-Cem/GC; G4- Biscem/ Bisco; G5- Panavia F2.0/Kuraray without pre-treatment and G6- Multilink Sprint/Ivoclar-Vivadent which were adhered to its respective indirect resin composite restoration, (G1-Clearfil AP-XIKuraray; G2- Filtek Z350/3M ESPE; G3- Gradia Direct XTM/GC; G4- AeliteTM/ Bisco; G5- Clearfil AP-XI Kuraray; G6- Tetric Ceram/ Ivoclar-Vivadent). The resin blocks were cemented and the sticks were obtained by tooth, with an area of adhesive interface of $0,8 \mathrm{~mm}^{2}( \pm 0,2)$.

\section{Results}

The mean values, submitted to Mann-Whitney and Kruskal-Wallis tests $(\alpha=5 \%)$ were in MPa after 24 hours: $G 1=9.66(A)$, G2 = $13.37(A)$ : $G 3=15.89(A) ; G 5=4.18(B) ; G 6=11.01(A)$ and after 1 year: $G 1=9.75(A), G 2=11.73(A) ; G 3=20.10(B) ; G 5=6.80(A) ; G 6=21.09$ (B). All G4 group presented pretest failures.

\section{Conclusion}

During the one year period, with the exception of BisCem, the self-adhesive resin cements were a favorable alternative for the adhesive cementation, standing out among these, the G-Cem and Multilink Sprint.

Indexing terms: Dentin. Resin cements. Tensile strength.

\section{RESUMO}

\section{Objetivo}

Avaliar, in vitro, a estabilidade da união de cimentos resinosos ao substrato dental através da resistência de união e análise em microscopia eletrônica de varredura (MEV).

\section{Métodos}

Cinquenta e quatro terceiros molares humanos, armazenados em água por um curto (24 horas) e longo período de tempo (1 ano), tiveram a face oclusal removida expondo a superfície dentinária. Os dentes foram distribuídos em seis grupos distintos: G1- Panavia F2.0 / Kuraray; G2- RelyX Unicem / 3M ESPE; G3- G-Cem / GC; G4- BisCem / Bisco; G5- Panavia F2.0 / Kuraray sem pré-tratamento e G6- Multilink Sprint / Ivoclar-Vivadent que foram aderidas ao seu respectivo restaurações de resina composta indireta, (G1- Clearfil AP-X/ Kuraray; G2- Filtek Z350 / 3M ESPE; G3- Gradia Direct X TM / GC; G4- Aelite TM / Bisco; G5- Clearfil AP-X / Kuraray; G6- Tetric Ceram / Vivadent Ivoclar-). Os blocos de resina foram cimentados e foram obtidos palitos, com área de interface adesiva de $0,8 \mathrm{~mm}^{2}( \pm 0,2)$.

\section{Resultados}

Os valores médios, submetidos à Mann-Whitney e Kruskal-Wallis testes $(\alpha=5 \%)$ foram em MPa após 24 horas: $G 1=9,66$ (A), G2 = 13,37 (A); $\mathrm{G} 3=15,89(\mathrm{~A}) ; \mathrm{G} 5=4,18(\mathrm{~B}) ; \mathrm{G} 6=11,01(\mathrm{~A})$ e depois de 1 ano: $\mathrm{G} 1=9,75(\mathrm{~A}), \mathrm{G} 2=11,73(\mathrm{~A}) ; \mathrm{G} 3=20,10(\mathrm{~B}) ; \mathrm{G} 5=6,80(\mathrm{~A}) ; \mathrm{G} 6=21,09$ (B). O grupo todo G4 apresentou falhas pré-teste.

\section{Conclusão}

Durante o período de um ano de investigação, os cimentos de resinosos auto-adesivos, exceto o Bis Cem, eram uma alternativa favorável para a cimentação adesiva, destacando-se entre estes o G-Cem e Multilink Sprint.

Termos de indexação: Dentina. Cimentos de resina. Resistência à tração.

\footnotetext{
${ }^{1}$ Universidade de Pernambuco, Departamento de Odontologia. Av. Gal. Newton Cavalcanti, 1650, 54753-220, Camaragibe, PE, Brasil. Correspondência para / Correspondence to: MA DURÃO. E-mail: <marciadurao.fop@gmail.com>.

${ }^{2}$ Universidade Federal de Pernambuco, Curso de Odontologia, Departamento de Prótese e Cirurgia Buco-Facial. Recife, PE, Brasil.
} 


\section{INTRODUCTION}

The clinical success of indirect restorations is attributed to the effective union between the mineralized tissues and luting systems, as defined by the combination of resin cement and adhesive agent. The differences in composition of resin cements and amounts of monomers diluents in functional groups and in the percentage of filler particles produce a significant variation in the commercial products properties ${ }^{1-2}$.

Currently, the resin luting agents can be classified as total-etching, self-etching and self-adhesives, according to the need of pretreatment of the tooth surface ${ }^{3}$. Selfadhesive cements have been indicated and used for yielding less sensitivity and reduced postoperative sensitivity ${ }^{4-5}$. According to the manufacturers, the functional monomers are able to chemically bind calcium from hydroxyapatite, which demineralize and infiltrates the dental substrate resulting in a micromechanical retention of the restoration ${ }^{6}$.

Adhesion degradation occurs via enzymatic attack of the collagen fibers not protected by the adhesive and dissolution of the resin components infiltrated into the dentin matrix. When acid etching agents are used to remove the smear layer, resulting in demineralization of the dentin surface, there is a risk that, the adhesive does not fully enclose the collagen fibers, which remain exposed? Such fibers become susceptible to the action of proteolytic enzymes present in the human dentin - endogenous metalloproteinases (MMPs) - resulting in the dissolution of the hybrid layer. The dissolution of the adhesive components can occur if there is an incomplete polymerization of the adhesive on the hybrid layer due to the presence of residual water in dentin during its application.

The main problem of adhesive restorations is their limited longevity. Several studies evaluate the bond strength of self-adhesive resin cements to the dental substrate in the short term. However, will the bond strength of self-adhesive resin cements remain stable in the long term? The analysis of this parameter is useful for a better understanding of the technology of self-adhesive luting.

The null hypothesis is that the bond strength of self-adhesive cements to dentin is similar to conventional cement, both initially and on the long term.

\section{METHODS}

We used five luting agents and their respective composites, described in Table 1. Fifty-four healthy human third molars were cleaned, disinfected $(0.5 \%$ ChloramineT, $24 \mathrm{~h})$, and stored in distilled water $\left(4^{\circ} \mathrm{C}\right)$. Each tooth was individually fixed to a sectioning machine (Elquip, São Paulo, Brazil) and sectioned perpendicular to its longitudinal axis using a flexible diamond disc (Extec, Einfield) under cooling to obtain a flat dentin area of medium depth. Forty-eight dentin discs of 3 $\mathrm{mm}$ thick were used for the $\mu$ TBS test, and six discs for SEM evaluation. A smear layer was produced on this surface using water abrasive papers number 180, 400 and 600 , for 30 s each under continuous cooling, at 300 rpm in a polishing machine (Risitec, São Paulo, Brazil). The dentin discs were randomly divided into 6 groups, according to the cementing strategy (Table 2). The aim of $\mathrm{G} 5$ was to test and evaluate the potential for selfadhesiveness of the self-etching cement Panavia F2.0, thus the dentin surface received no treatment.

Restorations with $5.5 \times 5.5 \times 2 \mathrm{~mm}$ of restorative materials described in Table 3 were performed with the aid of a two-piece matrix. The resin blocks were photoactivated for 40s on each side (VIP Junior/Bisco$600 \mathrm{~mW} / \mathrm{cm}^{2}$ ). The restoration surface in contact with the dentin was roughened with a diamond point, and then submitted to an ultrasonic bath in distilled water for $10 \mathrm{~min}$. The resin blocks were cemented onto the dentin in accordance with the respective manufacturer's recommendations. The pressure exerted on the restoration was standardized at $40 \mathrm{~g} / \mathrm{mm}^{2}$ using a device specially developed for this purpose (Figure 1).

The specimens were stored in distilled water at $37^{\circ} \mathrm{C}$ for $24 \mathrm{~h}$. Half of the specimens were stored for 24h, while the other half were stored for 1 year. Using a diamond disk (Extec, Einfield-thickness=0.3mm), the tooth-restoration set was sectioned vertically, in perpendicular direction to the adhesive interface, to obtain 16 test specimens (sticks), with an adhesive interface area standardized at $0.8 \mathrm{~mm}^{2}$. The number of specimens obtained for each tooth varies due to differences in the dentin surface area.

To perform the $\mu$ TBS test, a fast-drying adhesive (Super Bonder Gel/Loctite, São Paulo, Brazil) was used to attach each stick to the two sides of the device for the microtensile test, which was attached to a universal test machine (KRATOS/São Paulo, Brazil). The test was conducted in two parts: after $24 \mathrm{~h}$ and 1 year after the luting procedure of composite resin blocks. The maximum load at rupture of each test specimen was recorded. The cross sectional bond area of the stick 
Table 1. Resin cements and resin composites used in this study.

\begin{tabular}{|c|c|c|c|c|}
\hline Cement / Lots & Composition & Resin / Batch & Composition & Manufacturer \\
\hline $\begin{array}{l}\text { Kit Panávia F2.0 } \\
(61166)\end{array}$ & $\begin{array}{c}\text { ED Primer 2.0 - ED Primer II A: HEMA, DP, } \\
\text { 5-NMSA, water, accelerator. ED Primer } \\
\text { B: 5-NMSA, gas, water, benzene sodium } \\
\text { sulfinateED Primer 2.OPanavia F2.0 - } \\
\text { Base: hydrophobic aliphatic and aromatic } \\
\text { dimethacrylate; aromatic sulfinate sodium } \\
\text { N, N-diethanol-p-toluidine, sodium } \\
\text { fluoride, functionalized glass, barium } \\
\text { silaniizado. Catalyst: MDP dimethacrylate } \\
\text { aromatic and aliphatic hydrophobic, } \\
\text { hydrophilic dimethacrylate, silanized silica, } \\
\text { photoinitiator, dibenzoyl peroxide. (70.8\% } \\
\text { filler particles, particles of } 2 \mu .\end{array}$ & $\begin{array}{l}\text { Clearfil AP-X } \\
\text { (01191A) }\end{array}$ & $\begin{array}{l}\text { Barium silanized } \\
\text { crystal, silanized } \\
\text { colloidal silica, } \\
\text { silanized silica, Bis- } \\
\text { GMA, TEGDMA, di- } \\
\text { camphorquinone. }\end{array}$ & $\begin{array}{c}\text { Kuraray, Osaka, } \\
\text { Japan }\end{array}$ \\
\hline $\begin{array}{l}\text { RelyX Unicem } \\
\quad(265704)\end{array}$ & $\begin{array}{l}\text { Powder: glass fillers, silica, calcium } \\
\text { hydroxide, self-curing initiators, } \\
\text { pigments, light-curing initiators }(\text { filler } \\
\text { load } 72 \% \text { wt, particle size }<9.5 \mu \mathrm{m} \text { ) } \\
\text { Liquid: methacrylated phosphoric esters, } \\
\text { dimethacrylates, acetate, stabilizers, self- } \\
\text { curing initiators, light-curing initiators }\end{array}$ & $\begin{array}{l}\text { Filtek Z350 } \\
\quad(7 \mathrm{KU})\end{array}$ & $\begin{array}{c}\text { Filler particles, } \\
\text { bisphenol A } \\
\text { polyethylene glycol } \\
\text { diether dimethacrylate, } \\
\text { diurethane } \\
\text { dimethacrylate, } \\
\text { bisphenol A di-glycidyl } \\
\text { ether dimethacrylate, } \\
\text { triethylene glycol } \\
\text { dimethacrylate and } \\
\text { pigment. }\end{array}$ & $\begin{array}{l}\text { 3M-Espe, Seefeld, } \\
\text { Germany }\end{array}$ \\
\hline G-CEM (0702171) & $\begin{array}{c}\text { Powder: fluoroaluminosilicate glass, } \\
\text { initiator, pigment Liquid: 4-MET, } \\
\text { phosphoric acid ester monomer, water, } \\
\text { UDMA, dimethacrylate, silica powder, } \\
\text { initiator, stabilizer }\end{array}$ & $\begin{array}{l}\text { Gradia DirectX } \\
(0705101)\end{array}$ & $\begin{array}{c}\text { UDMA (15-30\% } \backslash 0 ; \\
\text { aluminum fluoride } \\
\text { silicate glass }(30-40 \%), \\
\text { silica powder }(10- \\
20 \%) ; \text { prepolymerized } \\
\text { loading }(20-30 \%) ; \\
\text { dimethacrylate }(0-5 \%) ; \\
\text { camphorquinone } \\
(<1 \%)\end{array}$ & $\begin{array}{l}\text { G-Cem } \\
\text { Tokyo, Japan }\end{array}$ \\
\hline $\begin{array}{c}\text { Biscem } \\
(0700006829)\end{array}$ & $\begin{array}{c}\text { Bis (hydroxyethyl methacrylate) } \\
\text { phosphate(base), tetraethylene glycol }\end{array}$ & $\begin{array}{c}\text { Aelite } \\
\text { (070008486) }\end{array}$ & $\begin{array}{l}\text { Bis-EMA }(15-40 \%) \\
\text { TEGDMA }(3 \%-7) ; \\
\text { glass particles }(50- \\
90 \%), \text { amorphous } \\
\text { silica }(1-20 \%)\end{array}$ & $\begin{array}{c}\text { Bisco, Schaumburg, IL } \\
\text { USA }\end{array}$ \\
\hline
\end{tabular}

was measured with a digital pachymeter (Digimess, São Paulo, Brazil). The transformation of the unit into load/ area values (MPa) was carried out subsequently. Figure 1 shows the experimental stages of this methodology. The machine was calibrated so that the load to be applied to the dentin bond line/restorative material occurred at a speed of $0.5 \mathrm{~mm} / \mathrm{min}$. The bond strength values of the tested specimens (sticks) were grouped per tooth as the arithmetic mean. As a consequence, each tooth was considered as a statistical unit. The data with reference to the bond area, bond strength and standard deviation received descriptive statistics and inferential treatment at a level of significance of $\alpha=0.05$ (5\%).
For SEM, the disks were divided into two halves along the diameter with the use of a diamond disk under cooling. Two hemidisks were distributed according to the 6 groups studied. The specimens were polished with abrasive papers (\#600 and \#1200). The following steps were then performed: resin/dentin interface etching with $37 \%$ phosphoric acid for $5 \mathrm{~s}$, washing under water for $10 \mathrm{~s}$; ultrasonic cleaning for $10 \mathrm{~min}$; immersion in $2.5 \%$ buffered glutaraldehyde with $0.1 \mathrm{M}$ sodium phosphate solution at $\mathrm{pH} 7.4$ and temperature of $4^{\circ} \mathrm{C}$ for $12 \mathrm{~h}$. After fixation, the samples were washed with $0.2 \mathrm{M}$ buffered phosphate for $1 \mathrm{~h}$, exchanging every $20 \mathrm{~min}$, and sequentially dehydrated in series of ascending 
Table 2. The Protocol of use.

\begin{tabular}{|c|c|c|c|}
\hline Group & Product & $\begin{array}{l}\text { Dentin Pre- } \\
\text { Treatment }\end{array}$ & Cimentation \\
\hline G1 & $\begin{array}{l}\text { Panavia F2.0 } \\
\text { (Kurarya) }\end{array}$ & $\begin{array}{l}\text { Prophylaxis with } \\
\text { pumice and water, } \\
\text { mix the ED Primer II } \\
\text { (Dispense } 1 \text { drop of } \\
\text { Liquid A and Liquid } \\
\text { B; apply on the tooth } \\
\text { structure and wait } 30 \\
\text { S, remove the excess } \\
\text { with paper towels, dry } \\
\text { with slight air jet }\end{array}$ & $\begin{array}{l}\text { Apply Clearfil Ceramic Primer on the piece } \\
\text { restorer with microbrush and remove excess; } \\
\text { dispense equal amounts of paste A and B of the } \\
\text { resin cement; manipulate for } 20 \mathrm{~s} \text {, cementing } \\
\text { the restoration under pressure } 40 \mathrm{~g} / \mathrm{mm}^{2} \text { for } \\
60 \mathrm{~s}, 37^{\circ} \mathrm{C} \text {; remove excesses, light curing each } \\
\text { interface and the occlusal for } 20 \mathrm{~s} \text {, apply the } \\
\text { Oxiguard II for 3min. and then remove material } \\
\text { with cotton pellet and water jet. }\end{array}$ \\
\hline $\mathrm{G} 2$ & $\begin{array}{l}\text { RelyX Unicem } \\
\text { (3M ESPE) }\end{array}$ & No pre-treatment & $\begin{array}{c}\text { Activate the capsule for } 4 \mathrm{~s} \text { in the metallic } \\
\text { device that comes with the kit; manipulate in } \\
\text { mechanical mill for } 15 \mathrm{~s} \text {, apply the cement to } \\
\text { dentin through the applier; cementing under } \\
\text { pressure } 40 \mathrm{~g} / \mathrm{mm}^{2} \text { for } 60 \mathrm{~s}, 37^{\circ} \mathrm{C} \text {; to remove } \\
\text { excesses; light cure each interface and occlusal } \\
\text { for } 20 \mathrm{~s} \text {. }\end{array}$ \\
\hline G4 & $\begin{array}{c}\text { BisCem } \\
\text { (Bisco) }\end{array}$ & $\begin{array}{l}\text { Prophylaxis with } \\
\text { pumice and water }\end{array}$ & $\begin{array}{l}\text { Dispense small amount of the material; dovetail } \\
\text { the applicator; apply the cement to the inner } \\
\text { surface of the restoration, cementing the part } \\
\text { under pressure } 40 \mathrm{~g} / \mathrm{mm}^{2} \text { and removing the } \\
\text { excess, immediate photoactivation of each } \\
\text { interface and occlusal for } 20 \mathrm{~s} \text {. }\end{array}$ \\
\hline G6 & $\begin{array}{l}\text { Multlink Sprint } \\
\text { (Ivoclar Vivadent) }\end{array}$ & $\begin{array}{l}\text { Prophylaxis with } \\
\text { pumice and water }\end{array}$ & $\begin{array}{l}\text { Apply cement, cement the restoring under } \\
\text { pressure } 40 \mathrm{~g} / \mathrm{mm}^{2} \text {; remove excess; cover } \\
\text { interfaces with oxygen blocking (Aqua gel / Kley } \\
\text { Hertz SA); immediate photoactivation of each } \\
\text { adhesive interface and occlusal for } 20 \text {, rinse } \\
\text { thoroughly to remove the blocker. }\end{array}$ \\
\hline
\end{tabular}

degrees of acetone. After dehydration, the specimens were submitted to a drying process through exchange with liquid $\mathrm{CO} 2$ by sublimation at the critical point, at a certain temperature and pressure (Balzers CPD-020 Critical Point drier, Linchenstein). The specimens were attached to metal stubs with double-faced carbon tape and gold-sputter coated using a vacuum metalizing appliance (CPD 030, Baltec, Blazers, Liechtenstein). After this, the specimens were taken to the SEM (JOEL, Tokyo, Japan), operating at 20kV. Standardized series of photomicrographs were taken at different magnifications (200 and 500X). The images were obtained from the record of the central region of the bond line of the specimens. 


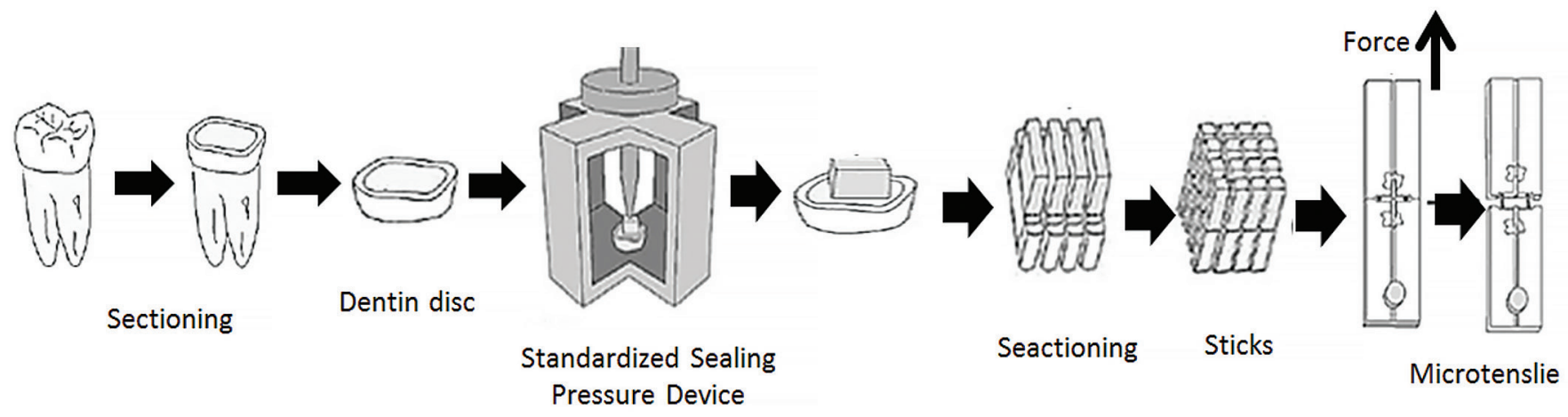

Figure 1. Schematic drawing of Tooth Preparation and Microtensile Bond Test.

\section{RESULTS}

The $\mu$ TBS means and standard deviations by groups are shown in Table 3. Analyzing the resin cements, the Kruskal-Wallis test revealed that after $24 \mathrm{~h}$ $(p=0.022)$, the use of $\mathrm{G} 5$, Panavia without any dentin pre-treatment, resulted in lower adhesion in comparison to the other groups. After 1 year of storage, the same test indicated significant statistical superiority for groups 3 and $6(p=0.033)$ compared to the other cements studied. The Mann-Whitney test $(p>0.05)$ indicated no statistically significant differences when comparing the averages of $24 \mathrm{~h}$ and 1 year of storage in distilled water. All specimens of $\mathrm{G} 4$ suffered failures before being submitted to the mechanical tests. In SEM it was possible to observe an homogeneous cement layer in G1, but no signs of hybrid layer formation were detectable (Figure 2A). Discontinuities were present along the interface with dentin and porosities could be noticed within the cement layer (G2), the hybrid layer was thin to undetectable and no tags were formed (Figure 2B). Good continuity could be seen between the cement layer and the dental substrate (Figure 2C), with no evidence of hybrid layer formation. Discontinuities were present along the interface with dentin. No detectable signs of hybrid layer formation were observed (Figure 2D).

Table 3. Mean (standard deviation) bond strength (MPa) of resin cements to dentin.

\begin{tabular}{|c|c|c|c|c|c|c|}
\hline Statistical Analysis & & & Groups & & & p - Value \\
\hline Mean & $9.66(2.22)^{\mathrm{A}}$ & $13.37(4.09)^{A}$ & $15.89(5.57)^{\mathrm{A}}$ & $4.18(1.99)^{\mathrm{B}}$ & $11.01(4.02)^{\mathrm{A}}$ & $p=0.022 *$ \\
\hline Mean & $9.76(4.30)^{\mathrm{A}}$ & $11.74(2.90)^{\mathrm{A}}$ & $20.10(6.42)^{\mathrm{B}}$ & $6.81(3.20)^{\mathrm{A}}$ & $21.10(6.81)^{\mathrm{B}}$ & $p=0.033^{*}$ \\
\hline
\end{tabular}



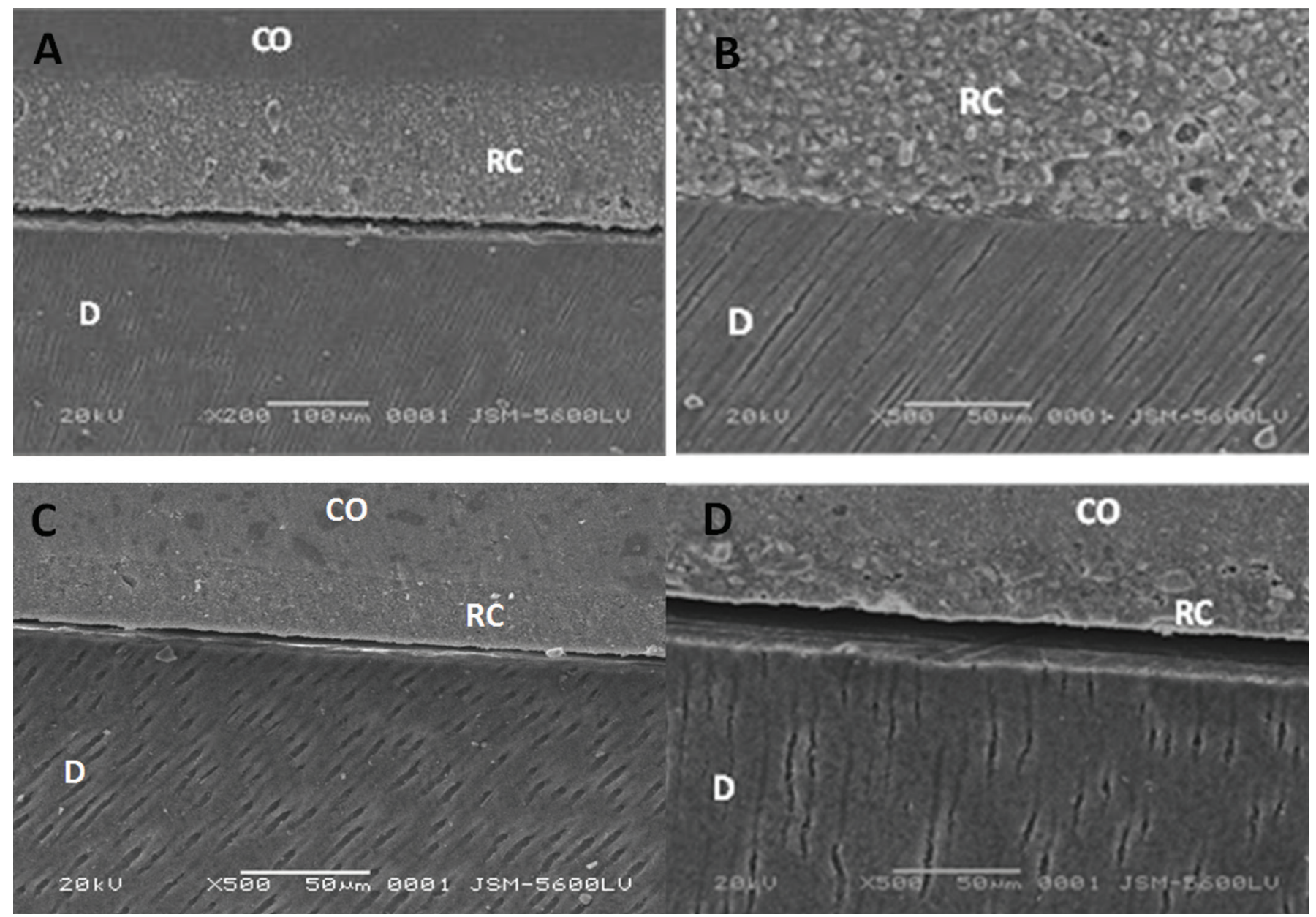

Figure 2. A) SEM micrograph (G1), Panavia, (X200, bar100um, Co=Composite overlay, C=Resin Cement, D=Dentin). B) SEM micrograph (G2), RelyX Unicem, (X500, bar50um, RC=Resin Cement, D=Dentin). C) SEM micrograph (G3), G Cem (X500,bar50 um, Co=Composite Overlay, RC=Resin Cement, D=Dentin). D) SEM micrograph (G6), Multlink Sprint (X500, bar 50 $\mathrm{mm}, \mathrm{Co}=$ Composite Overlay, RC=ResinCement, D=Dentin).

\section{DISCUSSION}

At $24 \mathrm{~h}$ of this study, Panavia (G1) achieved a capacity of adhesion similar to that found by Goracci et al. ${ }^{4}$ The primer Panavia consists of three amphiphilic monomer (HEMA, MDP and 5-NMSA) with low molecular weight, the latter being responsible for the dentin demineralization. According to Yoshida et al. ${ }^{8}$, the hydroxyapatite remaining after the product application may serve as a receptor for the chemical interaction with functional monomers, and subsequently contribute to the adhesive performance in addition to micro-mechanical hybridization.

In this study, after 24 hours, the Panavia F2.0 (G1), which is used in combination with the ED primer 2.0, showed union capacity numerically similar to that reported by Goracci et al. ${ }^{4}$. The primer of Panavia F2.0 consists of three amphiphilic monomers (HEMA, MDP and 5-NMSA) with low molecular weight, the latter being responsible for the demineralization of the dentin. According to Hiraishi et al. $^{3}$, through the microscopic observation of the treated dentin surface and the measurement of its permeability, it is possible to establish that the ED primer 2.0 is able to provide a moderate demineralization with dissolution of the layer and smear plugs. In 2007, Al-Assaf et al. ${ }^{11}$ showed that the extent of demineralization provided by this material is $51.99 \%$ of the dentin and the thickness of the hybrid layer is $0,95 \mu \mathrm{m}$.

In the short term, Panavia F2.0 without prior primer application (G5) had statistically significant lower bond strength when compared to G1, which followed the manufacturer's recommendations.

According to Monticelli et al. ${ }^{9}$, although the mechanism of adhesion seemed similar for all the selfadhesive cements, these materials are still relatively new and detailed information on its composition and adhesive property are limited. Still according to the same authors, 
these cements contain phosphoric acid methacrylate, which has the ability to react with the hydroxyapatite. This ester is not only able to decalcify hydroxyapatite, but may also chemically adhere to it allowing a micromechanical retention ${ }^{10}$. However, in Monticelli et al. ${ }^{9}$, no evidence of demineralization and infiltration in the dentin was found for the self-adhesive resin cements evaluated in this study.

In a study by Mazzitelli', a 30-days analysis of the BisCem one $\mu$ TBS 2.4 MPa obtained $68 \%$ of failure in the pretest, while the present study obtained a $100 \%$ failure rate in the pretest. However, the application of $5 \mathrm{~min}$ of autopolimerization and then 40s of photoactivation may have enhanced numerically the union capacity of this cement. In this study, the light curing immediately after cementation of their respective indirect restorative materials (composite), may have contributed to the occurrence of $100 \%$ of pre-testing failures. This can be explained by the limited penetration ability of the cement into the tooth structure when polymerization is performed immediately.

The RelyX Unicem may set the reaction in two ways. The free radical polymerization can be initiated by exposure to visible light or redox mechanism. There is also an acid-base reaction between the metal ions of the non-silanized glass particles fluorine aluminum silicate and the phosphate radical of methacrylate generated by the water produced during the neutralization reaction of the phosphate monomer, that is important for its long-term stability regarding bond strength to dentin ${ }^{11}$.

Among the cements tested in this study, the GCem showed the greatest capacity of adhesion to dentin. For Mazzitelli et al. ${ }^{6}$, the presence of water in the chemical composition of this cements could explain the results obtained since it is important to promote the ionization of existing acidic monomers, thus reducing the necessary time for the interaction with the dental substrate. Furthermore, the presence of the acid functional monomer 4-META in the composition, although a high molecular weight particle, could also have contributed to the chemical reaction with the dentin.

This monomer is capable of adhering to the calcium ions of the apatite through a reaction of chelation 9 . Yoshida et al.8 found that the application of 4-META hydroxyapatite for 30 min increased the carbon bonds energy in comparison with the application for 30s. In the same year Abo, Uno and Sano evidenced that an adhesive containing the 4-META produced similar performance to dentin when compared to one containing MDP ${ }^{12}$. This may indicate that the potential formation of the hybrid layer is practically the same for these two components.

Thus, differences in the chemical composition of these cements are indeed able to provide different results for bond strength. A long period of storage simulating oral conditions is necessary to evaluate dental composites. However, to simulate the time of permanence in the oral cavity expected for these materials, a storage time of five to ten years would be necessary. This time interval is unfeasible, since every year new materials are commercially available. Thus, evaluation results for a ten-year period were not relevant. The storage in water for 1 year does not decrease the bond strength of self-adhesive resin cements to dentin. Conversely, the humidity conditions can change the bond strength to dentin; however, these results are productdependent ${ }^{13}$.

Acid neutralization in cement is a key factor for its hydrophobicity and to guarantee that it remains intact in a humid environment. Acid materials retain some degree of hydrophilicity that leaves them prone to capture water, expand and degrade their structural matrices ${ }^{14}$. For cements RelyXUnicem and G-Cem, a work published by Han et al. ${ }^{15}$ confirm an increase in their $\mathrm{pH}$ within $48 \mathrm{~h}$ following photoactivation.

A study of the shear strength of resin cements demonstrated highly divergent behavior to dentin. While some of the self-adhesive resin cements had similar values of bond strength to the conventional cement Panavia, others showed lower values before and after aging, in the long term $^{16}$. Not all self-adhesive resin cements can be a valid alternative to conventional cement for binding silica based glass-ceramic to dentin ${ }^{17}$. Regarding the Multilink Sprint, although no statistical difference was showed for the two periods studied, there was a numerical increase in adhesive resistance after 1 year of storage. However, the lack of information provided by the manufacturer with respect to the monomers that compose this cement do not allow a further discussion to justify the result. We can argue, though, that the acid neutralization of RelyXUnicem and G-Cem must have contributed to their adhesive stability.

\section{CONCLUSION}

The self-adhesive resin cements showed higher adhesion to dentin in the short term when compared to self-etching cement (Panavia F2.0), with the exception of BisCem. After one year storage, the self-adhesive cements G-Cem and Multilink Sprint showed the highest bond 
strength values to dentin, standing out among the other resin cements evaluated in the same period. In the longterm, the self-adhesive resin cements demonstrated to be stable with respect to bond strength, presenting itself as a favorable alternative.

\section{ACKNOWLEDGEMENTS}

FACEPE and CNPq through the scholarship.

\section{Collaborators}

R BRAZ, advisor. FB SOUZA, he worked on the methodology and SEM analysis. GLS GOMES, she worked on the methodology and SEM analysis. MA Marcia Durão - Monitoring methodology and was responsible for preparing the paper and its submission to the RGO. EA LIMA, worked on the methodology and collaboration in preparing the article.

\section{REFERENCES}

1. Fonseca RG, Cruz CAS, Adabo G L. The influence of chemical activation on hardness of dual-curing resin cements. Braz. Oral Res. 2004;18(3):228-32. doi: 10.1590/S180683242004000300009

2. Aguiar TR, Di Francescantonio M, Bedran-Russo AK, Giannini, M. Inorganic composition and filler particles morphology of conventional and self-adhesive resin cements by SEM/ EDX. Microsc Res Tech. 2012;75(10):1348-52 doi: 10.1002/ jemt.22073.

3. Hiraishi N, Yiu CKY, King NM, Tay FR. Effect of pulpal pressure on the microtensile bond strength of luting resin cements to human dentin. Dent Mater. 2009;25(1):58-66. doi: 10.1016/j. dental.2008.05.005

4. Goracci C, Cury AH, Cantoro A, Papacchini F, Tay FR, Ferrari M. Microtensile bond strength and interfacial properties of self-etching and self-adhesive resin cements used to lute composite onlays under different seating forces. J Adhes Dent. 2006;8(5):327-35.

5. Christensen GJ. Should resin cements be used for every cementation? J Am Dent Assoc. 2007;138(6):817-9. doi: 10.14219/jada.archive.2007.0271

6. Mazzitelli C, Monticelli F, Osório R, Casucci A, Toledano M, Ferrari M. Effect of simulated pulpal pressure on self-adhesive cements bonding to dentin. Dent Mater. 2008;24(9):1156-63. doi: 10.1016/j.dental.2008.01.005

7. Carrilho MRO, Carvalho RM, De Góes MF, Di Hipólito V, Geraldeli S, Tay F R, et al. Chlorhexidine preserves dentin bond in vitro. J Dent Res. 2007;86(1):90-4.

8. Yoshida Y, Nagakane K, Fukuda R, Nakayama Y, Okazaki M, Shintani $\mathrm{H}$, et al. Comparative study on adhesive performance of functional monomers. J Dent Res. 2004;83(6):454-8. doi: $10.1177 / 154405910408300604$

9. Monticelli F, Osorio R, Mazzitelli C, Ferrari M, Toledano M. Limited decalcification/diffusion of self-adhesive

cements into dentin. J Dent Res. 2008;87(10):974-9. doi: $10.1177 / 154405910808701012$

10. Fu B, Sun X, Qian W, Shen Y, Chen R, Hannig M. Evidence of chemical bonding to hydroxyapatite by phosphoric acid esters. Biomaterials. 2005;26(25):5104-10. doi:10.1016/j. biomaterials.2005.01.035

11. Al-Assaf K, Chakmakchi M, Palaghias G, Karanika-Kouma A, Eliades $\mathrm{G}$. Interfacial characteristics of adhesive luting resins and composites with dentine. Dent Mater. 2007;23(7):82939. doi: 10.1016/j.dental.2006.06.023

12. Abo T, Uno S, Sano H. Comparison of bonding efficacy of an all-in-one adhesive with a self-etching primer system. Eur J Oral Sci. 2004;112(3):286-92. doi: 10.1111/j.16000722.2004.00126.x

13. André $C B$, Aguiar TR, Ayres APA, Ambrosano GMB, Giannini $M$. Bond strength of self-adhesive resin cements to dry and moist dentin. Braz Oral Res. 2013;27(5):389-95. doi: 10.1590/ S1806-83242013000500002.

14. 3M ESPE. Scientific update: RelyX Unicem self-Adhesive universal resin cement [text internet]; 2006.

15. Han L, Okamoto A, Fukushima M, Okiji T. Evaluation of physical properties and surface degradation of self-adhesive resin cements. Dent Mater J. 2007;26(6):906-14. doi: 10.4012/ dmj.26.906

16. Sarr M, Mine A, De Munck J, Cardoso Mv, Kane Aw, Vreven $J$, et al. Immediate bonding effectiveness of contemporary composite cements to dentin. Clin Oral Investig. 2010;14(5):569-77. doi: 10.1007/s00784-009-0327-8

17. Hitz T, Stawarczyk B, Fischer J, Hämmerle CH, Sailer I. Are self-adhesive resin cements a valid alternative to conventional resin cements? A laboratory study of the long-term bond strength. Dent Mater. 2012;28(11):1183-90. doi: 10.1016/j. dental.2012.09.006. 